\title{
La colaboración de las organizaciones públicas del conocimiento con las empresas: una mirada de empresarios
}

\section{Rodolfo García Galván*, Ricardo Lindquist SÁNCHez** y \\ Marcela Morales Páez**}

\section{RESUMEN}

Se indagaron las percepciones de los empresarios del noroeste de México sobre la colaboración tecnocientífica entre las organizaciones públicas del conocimiento y las empresas. Fue un estudio cuantitativo exploratorio, basado en la técnica cualitativa de entrevistas semiestructuradas. Se identificaron problemas de oferta y demanda de conocimiento que dificultan la colaboración tecnocientífica. Las modalidades de colaboración más mencionadas fueron las prácticas profesionales, la educación dual y la capacitación continua. Los empresarios identificaron, en primer lugar, los beneficios de corto plazo, como la contratación de graduados. Señalaron que para impulsar a la colaboración tecnocientífica academia-empresas, se requieren nuevas políticas, como la modificación del esquema de incentivos, la profesionalización y la especialización de los gestores de las funciones y actividades de colaboración universitaria, el mejoramiento de las estrategias de difusión-comunicación interorganizacional, y fomentar habilidades transversales en la formación que sean de interés para las empresas.

Palabras clave: colaboración tecnocientífica, oferta y demanda de conocimiento, organizaciones del conocimiento, perspectiva de empresarios.

Clasificación JEL: L24, O32, O35.

\footnotetext{
*Investigador Cátedra Conacyt, adscrito al Instituto de Investigación y Desarrollo Educativo de la Universidad Autónoma de Baja California, México. Correo-e: rodolfo.garcia.galvan@uabc. edu.mx

** Instituto de Investigación y Desarrollo Educativo de la Universidad Autónoma de Baja California, México. Correo-e: rlindquist@uabc.edu.mx, morales.marcela@uabc.edu.mx, respectivamente.
} 


\section{ABSTRACT \\ Collaboration of public knowledge organizations with firms: an entrepreneurial perspective}

The aim of the paper was to inquire into the perceptions of entrepreneurs, in northwestern Mexico, on techno-scientific collaboration between public knowledge organizations and firms. It was an exploratory quantitative study based on the qualitative technique of semi-structured interviews. The analysis was based on the theoretical-empirical review of previous studies in Latin America and Mexico. Main results: knowledge supply and demand problems were found that hinder technoscientific collaboration, the most mentioned collaboration modalities were professional practices, dual education and continuous training; employers first identified short-term benefits such as hiring graduates; likewise, they pointed out that to give a greater boost to the academyfirms techno-scientific collaboration, new policies are required such as modifying the incentive scheme, professionalization and specialization of the managers of university collaboration functions and activities, improvement of the strategies of interorganizational disseminationcommunication, and fostering transversal skills in training that are of interest to firms.

Keywords: technoscientific collaboration, supply and demand of knowledge, knowledge organizations, entrepreneurial perspective.

JEL Classification: L24, O32, O35.

\section{INTRODUCCIÓN}

Aunque la investigación sobre la colaboración de las organizaciones públicas del conocimiento (universidades y centros de investigación) con las empresas se ha extendido y profundizado, aún quedan preguntas en el aire. Por ejemplo, la mayoría de los trabajos han tenido como objeto de estudio las organizaciones académicas y, en menor medida, a las empresas, pero desde la perspectiva de los académicos. Por tanto, el propósito de este documento fue indagar la perspectiva de los empresarios sobre la colaboración tecnocientífica entre las organizaciones públicas del conocimiento (OPC) y las empresas.

Históricamente, las economías latinoamericanas se han caracterizado por su baja capacidad innovadora y, en general, se supone que 
los actores económicos son adversos a asumir los riesgos que conlleva involucrarse en los proyectos tecnocientíficos. Desde los 1990, en el ámbito de las políticas científicas y tecnológicas y de la educación superior, se ha persuadido sobre el papel que pudieran jugar las OPC para fomentar la intensidad tecnocientífica de los bienes y servicios que se producen y se consumen en la región. Sin embargo, pocas veces se considera la naturaleza y las capacidades de las OPC y de las empresas en las distintas regiones de los países latinoamericanos, lo cual impide acelerar la carrera tecnocientífica. Aunque se han desarrollado diversos estudios sobre las OPC, los abordajes sobre la perspectiva de los empresarios son reducidos, por lo que este trabajo se une a los esfuerzos de ampliarlos.

En ese sentido, se partió de la siguiente pregunta: ¿cuáles fueron los rasgos idiosincráticos más sobresalientes que matizaron las relaciones colaborativas de las OPC con las empresas en la región noroeste de México, caracterizada por la ausencia general de empresas innovadoras? En general, la literatura económica destaca que América Latina carece de empresas basadas en el conocimiento, y que lo que prevalece es la actividad manufacturera, maquiladora y de servicios; por lo tanto, buscar argumentos y evidencias de lo que genera esa problemática, en el ámbito regional, fue fundamental en esta investigación. Asimismo, el objetivo fue explorar las percepciones de los empresarios acerca de la colaboración tecnocientífica (CT) de las OPC con las empresas, en el marco de una economía basada en servicios, manufactura y maquila.

Para profundizar sobre la CT en una región de un país latinoamericano fue necesario contextualizar teórica y empíricamente la evolución de la discusión; se partió de los planteamientos abstractos y se llegó hasta la concreción de la CT OPC-empresas en regiones latinoamericanas específicas. Recoger las percepciones y opiniones de empresarios involucrados en el asunto resultó tener alta relevancia metodológica. De esta manera, se hizo eco de una sugerencia de Bodas et al., quienes llamaron la atención sobre la necesidad de investigar la perspectiva de la industria con la finalidad de entender mejor las motivaciones y los obstáculos para colaborar con las universidades (2013: 451).

El documento se estructura en cuatro apartados. En el primero se realiza una contextualización teórica y conceptual, que incluye, primero, una discusión teórico-conceptual, y luego un panorama de lo que ha sucedido con la CT OPC-empresas en el ámbito latinoameri- 
cano, así como en el nacional y en Baja California. La segunda sección expone la metodología desplegada, y la tercera muestra los resultados y la discusión. Finalmente, se presentan las conclusiones.

\section{Contextualización teórico-CONCEPTUAL}

\subsection{Una perspectiva general}

Desde los 1940 se reconoció el papel de la ciencia en la solución de diversos problemas de la humanidad (Bush, 1999); y más aún, R. Nelson (1959) argumentó que, en el largo plazo, la ciencia básica genera los mayores beneficios sociales marginales; pero, al igual que Arrow (1962), sostenía que el financiamiento de la investigación científica no deviene de la economía competitiva del libre mercado. De hecho, la producción, difusión e intercambio del conocimiento no puede confiarse a la autorregulación del mercado.

Históricamente, el conocimiento tecnocientífico ${ }^{1}$ ha sido la base para el desarrollo industrial y la competitividad. Los avances científicos y tecnológicos son fundamentales para el crecimiento, y el gobierno tiene que impulsarlos para asegurarlo. Así, la habilidad de inventar e innovar -generar nuevos conocimientos e ideas que se conviertan en productos, procesos y organizaciones-, ha impulsado siempre el desarrollo (Audretsch et al., 2002; David y Foray, 2002).

Desde las persuasiones de Bush (1999), hasta los trabajos de Dasgupta y David (1994), Audretsch et al. (2002) y Foray (2004), se ha reconocido el papel del Estado-gobierno para corregir las fallas de mercado (subinversión privada, mercados incompletos, monopolios, externalidades, bienes públicos) inherentes a la producción, difusión e intercambio de conocimiento.

De 1980 en adelante, se han hecho esfuerzos sistemáticos para intensificar la contribución del conocimiento universitario al crecimiento (Audretsch et al., 2002; David y Foray, 2002; Mowery y Sampat, 2005); por ejemplo, al fomentar el patentamiento. Asimismo, se ha persuadido a las OPC de incorporar entre sus finalidades la de

1 Esta noción refiere el proceso continuo que puede existir desde el desarrollo de la ciencia básica hasta sus aplicaciones en los ámbitos prácticos, los desarrollos tecnológicos y la comercialización de bienes y servicios derivados de las actividades científicas y tecnológicas (García-Galván, 2014; Morales, 2019). 
contribuir al desarrollo económico (Etzkowitz, 2003; García-Galván, 2018), que se ha denominado Segunda revolución académica.

Para David y Foray, la intensificación de la colaboración ${ }^{2}$ OPCempresas es una expresión de la economía basada en el conocimiento, en tanto que la mayoría de las comunidades del conocimiento trasciende las organizaciones convencionales, y los miembros de las primeras (investigadores universitarios) trabajan simultáneamente en las empresas (2002: 479). Al introducirse en las organizaciones convencionales, estas comunidades se vuelven agentes del cambio para su industria y la economía en general.

Sin embargo, en la división internacional del trabajo tecnocientífico sobresalen los países occidentales desarrollados, en donde los acuerdos colaborativos basados en el conocimiento han registrado un crecimiento exponencial desde 1980 (Arocena y Sutz, 2005; Audretsch et al., 2002; Caloghirou et al., 2008). Sin embargo, esta colaboración conlleva un componente informal, pues implica intercambios basados en conocimiento tácito (David y Foray, 2002; Foray, 2004). Entonces, en los mismos países desarrollados, las formas preeminentes de colaboración con las empresas no necesariamente se relacionan con las modalidades más conocidas y promocionadas como el patentamiento, las licencias tecnológicas y las empresas spin-offs. Por ejemplo, Bekkers y Bodas (2008), y Perkmann et al. (2013) destacan que hay una gran variedad de formas en las que las OPC pueden colaborar, las cuales incluso están lejos de las patentes conjuntas o del licenciamiento de las patentes otorgadas.

De hecho, las oficinas de transferencia de tecnología (OTT) que impulsan el patentamiento se encuentran entre los canales menos importantes para favorecer la colaboración mediante la transferencia de conocimiento. Por lo anterior, tomar en cuenta sólo estos instrumentos sería inapropiado. Factores como la disponibilidad de revistas científicas o el fomento de la participación en conferencias científicas para empresas industriales podrían ser más efectivas para promover la conciencia de las empresas sobre el conocimiento. Además, la contra-

2 Se entiende por colaboración la acción conjunta entre dos o más agentes para lograr objetivos o metas comunes. En el proceso de la colaboración se pueden poner a disposición de los participantes esfuerzos laborales, recursos, capacidades, destrezas, capital e infraestructura. En la colaboración tecnocientífica, como la que aquí se analiza, los objetivos y metas que persiguen las OPC y las empresas son desarrollos innovativos y tecnológicos conjuntos. 
tación de estudiantes, así como el apoyo para que realicen sus tesis serían de gran interés para las empresas que necesitan conocimiento universitario específico para absorberlo ${ }^{3}$ en sus productos, procesos, y organización (Bekkers y Bodas, 2008: 1849).

De acuerdo con estos autores, las principales formas de colaboración mediante la transferencia de conocimiento de las OPC a las empresas son: publicaciones científicas en revistas o libros arbitrados $\mathrm{y}$ otras publicaciones, documentos de patentes, contactos personales informales, contratación de graduados y posgraduados, participación en conferencias y talleres, y proyectos conjuntos de I+D. No obstante, los diversos canales de transferencia conllevan matices, en función de los campos del conocimiento y de los sectores industriales de las firmas con las cuales se colabora (Bekkers y Bodas, 2008: 1842). En efecto, la velocidad del cambio tecnológico no es uniforme, y el conocimiento tecnocientífico tiende a ser fundamental para los nuevos sectores que impulsan el crecimiento cada vez mayor de la economía (David y Foray, 2002: 472-473).

Los sectores en que la creación del conocimiento se agiliza son aquellos donde las interrelaciones de la ciencia y la tecnología son estrechas e intensas. De este modo, hay una tendencia creciente del patentamiento universitario, especialmente en las áreas de biotecnología, farmacéutica, implementos médicos y programas de cómputo (David y Foray, 2002: 483-484).

En sintonía con lo anterior, cuando los estudiantes se convierten en empleados o consultores de las firmas, son un medio de transferencia de la tecnología y los descubrimientos científicos, y proporcionan enlaces duraderos que mantienen unidos a los científicos de las facultades con las empresas en las que trabajan (Audretsch et al., 2002). En este sentido, García-Galván (2014) sostuvo que entre mayor sea la participación de los graduados y posgraduados en la actividad económica, la probabilidad de contar con productos y procesos de mayor valor agregado, con alto contenido innovativo, también se incrementa.

En la perspectiva de Perkmann et al., las diferentes formas de colaboración mediadas por el conocimiento entre las OPC y las empresas

\footnotetext{
Las capacidades de absorción pueden entenderse como los conocimientos, las habilidades y destrezas, así como los recursos con los que cuenta una organización para aprovechar (explorar y explotar) otros conocimientos, recursos y capacidades disponibles.
} 
pueden aglutinarse en lo que ellos denominan compromiso académico; las interacciones incluyen actividades como la investigación bajo contrato y la consultoría, así como labores informales, entre las que se encuentran el asesoramiento personalizado y el establecimiento de contactos con los profesionales (2013: 424).

\subsection{La discusión académica en el contexto latinoamericano}

A continuación se presentan algunos retos para que la oferta de conocimiento de las OPC permita una mayor colaboración con las empresas:

a. A inicios del año 2000, dos tercios de la población mundial no contaban con computadora ni servicios de internet. Pero un problema de mayor complejidad es dotar a los individuos con capacidades que les permitan interpretar, seleccionar y utilizar la información para mejorar su calidad de vida (David y Foray, 2002: 481). Así, las sociedades latinoamericanas se han revelado, a través de la historia, como profundamente desiguales, en la medida en que los cambios tecnológicos sólo tienen impacto en los grupos de élite.

b. Insuficiente cobertura en educación superior (CEPAL, 2010). Son escasos los países que han superado una tasa de 50\% (por ejemplo, Argentina, Chile, Costa Rica, Uruguay).

c. El financiamiento, como proporción del PIB, es reducido en comparación al promedio de los países de la OCDE (García-Galván, 2015); únicamente Brasil ha logrado tasas superiores a $1 \%$, pero no se ha presentado continuidad histórica (Bodas et al., 2013).

d. Las economías más grandes de la región se especializan en actividades económicas que, salvo excepciones, no provocan una gran demanda de conocimiento tecnocientífico.

e. La reconversión productiva necesaria para fomentar una mayor demanda de conocimiento sigue pendiente, y esto se ve reflejado en el reducido índice per cápita de investigadores en la región (CEPAL, 2010; García-Galván, 2014, 2015).

f. La infraestructura y el equipamiento tecnocientífico de la región es insuficiente y en algunos países inexistente.

Históricamente, las OPC latinoamericanas se han desarrollado en el marco de sociedades pobres, desiguales e inequitativas, de sectores económicos rezagados y de entornos políticos poco democráticos, 
corruptos y autoritarios. ${ }^{4}$ En este contexto, las universidades públicas han contribuido a la ciudadanización y democratización de la región y, salvo algunos periodos cortos, han presentado un alto compromiso con las demandas sociales más significativas. Pese a todo, desde 1990 las OPC en América Latina se han propuesto avanzar en la consolidación de la colaboración tecnocientífica con las empresas. En este sentido, se espera que las OPC latinoamericanas contribuyan a cambio de ciertos beneficios, no necesariamente pecuniarios, que las firmas brindan a sus contrapartes (CEPAL, 2010: 34).

Ante las distorsiones generadas por el subdesarrollo económico, las OPC se han posicionado como actores clave en el proceso de desarrollo tecnológico y de alcance en sectores industriales específicos, por medio de diferentes formas de colaboración, pero destaca la formación de recursos humanos. ${ }^{5}$ De hecho, las OPC son una fuente de información para los procesos de innovación, particularmente para la industria farmacéutica, la electrónica, la química y la automotriz. En consecuencia, la colaboración de las OPC con las industrias emergentes (las más productivas en el desarrollo de nuevos productos y en la formación tecnocientífica), proviene de las misiones tradicionales: la enseñanza y la investigación (Bodas et al., 2013: 444, 446, 451).

Además de las persuasiones a las OPC latinoamericanas para que contribuyan directamente a la competitividad industrial, la realidad es que éstas, en varios países, han actuado como el último dique para que los problemas sociales (pobreza, desnutrición, desempleo, enfermedades infecciosas, entre otros) no se desborden. También han contribuido al proceso de recuperación de las pequeñas y medianas empresas después de las crisis que amenazan su existencia. Un ejemplo claro de esta situación lo describen Riquelme y Langer (2008), y Naidorf (2014), al aludir a lo sucedido en Argentina en la profunda crisis económica de inicios de siglo.

4 La pobreza, inequidad, desigualdad, salud y educación deficientes crean demandas específicas para las OPC. Por lo tanto, la investigación requiere orientarse a las necesidades sociales de los usuarios. La demanda ejercida por las firmas sobre las OPC puede no estar en concordancia con las necesidades de la mayoría (Arza, 2010: 474).

5 Los estudiantes de posgrado son el mejor vínculo entre las OPC y las empresas de la industria emergente, porque proponen nuevos proyectos y porque, al trabajar en las empresas, son concientes de la importancia de las OPC para fomentar el desarrollo de nuevos productos (Bodas et al., 2013: 449). 
De acuerdo con la CEPAL, pueden distinguirse tres niveles ascendentes en las formas o modalidades de colaboración OPC-empresa. El primer nivel implica las modalidades poco complejas que se conforman por los flujos de recursos humanos de las OPC a las firmas, los contactos informales entre los poseedores del conocimiento y los usuarios en la industria, y las actividades de difusión y divulgación del conocimiento. En segundo lugar están las modalidades de complejidad media, como servicios especializados (asesorías tecnocientíficas, asistencia técnica, consultoría y uso compartido de equipo [pruebas y análisis específicos, controles de calidad]) que implican flujos unidireccionales y soluciones de corto plazo para problemas productivos; proyectos conjuntos de I+D, investigación por contrato y participación conjunta en el desarrollo de parques tecnocientíficos; estas modalidades fortalecen los vínculos de largo plazo y su finalidad es avanzar en el desarrollo de las capacidades tecnocientíficas y de innovación, con flujos de conocimiento que impliquen bidireccionalidad. En tercer nivel están las formas altamente complejas, como los licenciamientos de propiedad intelectual (patentes), las spin-offs y los centros mixtos de investigación; en este nivel se enfatiza la comercialización del conocimiento de las OPC y se desarrolla en sectores muy dinámicos e intensivos en la tecnociencia; asimismo, implica flujos bidireccionales y una colaboración basada en conocimiento (CEPAL, 2010: 65-80).

La clasificación de la CEPAL (2010) coincide con el plano propuesto por Arza, en el que se establece que cuando las empresas (latinoamericanas) asumen una estrategia pasiva respecto al uso de los resultados de las OPC y sus recursos para una operación más eficiente, normalmente se ubican en los cuadrantes 1 y 2 localizados a la izquierda del eje vertical (2010: 476-477). En el cuadrante 1, la colaboración se asocia con la provisión de servicios tecnocientíficos por recursos financieros, donde los flujos del conocimiento van de las OPC a las firmas (consultoría, equipo para control de calidad, pruebas y monitoreo, etc.). El cuadrante 2 es un canal convencional porque se asemeja a las formas tradicionales en que las firmas se benefician de las OPC (contratación de graduados, conferencias, publicaciones, etc.). Los flujos del conocimiento van de las OPC a las firmas. Después se encuentran las modalidades basadas en mayor valor agregado en conocimiento e implican una estrategia proactiva de las empresas, como la investigación conjunta, el licenciamiento de propiedad intelectual y las firmas spin-offs; pero, 
como lo señalan García-Galván (2018) y García-Galván et al. (2018), se mantienen a un nivel simbólico.

Dentro de la heterogeneidad -en países como Brasil, México, Argentina y Cuba-, algunas OPC han avanzado al nivel más complejo; sin embargo, el grueso de las OPC se mantiene en el primer nivel. Así, la perspectiva crítica de la colaboración OPC-empresas ha enfatizado la necesidad de atender la demanda de productos y actividades tecnocientíficas.

\section{El problema de la demanda}

Los países pobres se encuentran estancados, en parte, por la debilidad en la demanda de conocimiento. Esta demanda deprimida hace difícil fomentar el aprendizaje para resolver problemas. En efecto, las naciones que sólo trabajan la oferta -por ejemplo, con la formación de científicos y tecnólogos- terminan cotribuyendo a la migración (Arocena y Sutz, 2010: 572).

Dada la debilidad de la demanda de mercado del conocimiento, en Latinoamérica una perspectiva de "universidad emprendedora" implica que las OPC sean persuadidas de desarrollar menos creatividad, en comparación con la de los países desarrollados (Arocena y Sutz, 2005: 583).

Es difícil para las OPC latinoamericanas cooperar con otras instituciones en la aplicación del conocimiento para el desarrollo, fundamentalmente porque hay pocos socios dispuestos a colaborar y, en general, la producción endógena de conocimiento no es valorada por las élites económicas y políticas (Arocena y Sutz, 2005: 585). Al respecto, Pérez (2010) lamenta que en México el trabajo de un político sea más valorado por la sociedad que el de un científico que pudiera aportar una solución novedosa y efectiva para un problema social o económico. Por su parte, Cereijido (2008) critica también que las sociedades latinoamericanas estén tan influenciadas por las religiones para tomar decisiones importantes, en tanto que la ciencia es desdeñada. Además, las firmas muestran poca preferencia por el conocimiento endógeno:

En el caso de las empresas latinoamericanas, su comportamiento en materia de empeño innovador se traduce en algunas debilidades del proceso de innovación. Este, por un lado, depende muy marcadamente de la compra de equipos o insumos, con un reducido esfuerzo interno de adaptación y mejora de tecnología. Por el otro, los 
niveles de cooperación con otros agentes públicos y privados, como proveedores, competidores, universidades y centros de investigación son notoriamente bajos. La debilidad en la cooperación es muy significativa, ya que, según la evidencia, las firmas que cooperan tienen también mayores probabilidades de innovar. Más aún, la baja inversión en investigación y desarrollo interna reduce las posibilidades de cooperar, ya que estas dependen en parte de la capacidad de la empresa para ofrecer activos tecnológicos complementarios (CEPAL, 2010: 52).

Asimismo, bajo las exigencias de una economía basada en el conocimiento, el panorama competitivo de las firmas latinoamericanas no parece prometedor si éstas se mantienen alejadas de las potencialidades universitarias. De este modo, "las empresas innovadoras necesitan cada vez más acceder al conocimiento y a los recursos producidos por las universidades y centros de investigación. En este sentido, el mantener un comportamiento proactivo y desarrollar vínculos fuertes con el mundo de la ciencia y la tecnología responde a la exigencia de fortalecer potenciales ventajas competitivas que sean sólidas y de largo plazo" (CEPAL, 2010: 62).

Si los países latinoamericanos desean incentivar la cooperación OPC-empresas, deben avanzar simultáneamente en la definición de estructuras productivas que exijan un mayor grado de conocimiento, lo que García-Galván (2014 y 2015) denomina reconversión productiva. En general, la especialización de la región en estructuras industriales poco intensivas en conocimiento propicia que no exista una gran demanda de servicios, procesos y productos derivados de las OPC; por consiguiente, es necesario promover una "cultura innovadora" en las empresas.

En América Latina, el factor que mejor explica la escasez de vínculos entre los actores con conocimientos y la producción es la debilidad de la demanda de conocimiento de las empresas. En esto influye de manera determinante la estructura productiva (Arocena y Sutz, 2010: 575).

Al respecto, Rodrik apunta que la innovación en el mundo en desarrollo no está limitada por la oferta sino por la demanda (2007, en Arocena y Sutz, 2010: 576). Entonces, la innovación se ve socavada por la falta de demanda de sus usuarios potenciales, es decir, los empresarios. Y la demanda de innovación es baja porque los empresarios perciben que las nuevas actividades son poco rentables. En este sentido, la oferta de conocimiento no crea su propia demanda. 
Dado lo anterior, las empresas innovadoras aún conforman una proporción pequeña. Las capacidades desarrolladas mediante las políticas tecnocientíficas ofertistas aún están subutilizadas por las empresas, que continúan siendo un mercado laboral marginal para los investigadores y, en el caso de las Pymes, para los graduados universitarios (Arocena y Sutz, 2010: 578). Lo anterior termina provocando un éxodo de científicos y tecnólogos latinoamericanos.

El mejoramiento de las capacidades innovadoras de las firmas es esencial para el desarrollo. No obstante, en los países latinoamericanos los obstáculos estructurales posicionan el umbral de riesgo percibido para iniciar esfuerzos innovadores intensivos en conocimiento a un nivel muy alto. ${ }^{6}$ En consecuencia, la demanda de conocimiento local continúa siendo muy débil. De este modo, las políticas tecnocientíficas ofertistas carecen de legitimidad. La inversión en I+D es difícil de legitimar si la sociedad en general no hace un uso extensivo de las capacidades basadas en el conocimiento endógeno (Arocena y Sutz, 2010: 579).

Es claro que el dinamismo promedio de las firmas latinoamericanas no puede compararse con las empresas de los países desarrollados. Sin embargo, la cooperación OPC-empresas puede ser efectiva únicamente si hay demanda proactiva del conocimiento en la industria. Las firmas extranjeras demandan tecnología de sus casas matrices, y muchas firmas locales prefieren importar tecnologías (Velho, 2003, en Arza, 2010: 474). Asimismo, la estructura productiva en América Latina no es intensiva en conocimiento tecnocientífico y, por lo tanto, genera pocos beneficios para las OPC y menores oportunidades de aplicación del conocimiento.

Recapitulando, aunado a la idiosincrasia de las OPC y de las firmas latinoamericanas, sea por falta de capacidades de absorción que se relacionan con las estrategias pasivas de las empresas, por una estructura productiva general que no fomenta el uso del conocimiento en los procesos industriales, por la deficiencia en las estrategias colaborativas

6 Entre las deficiencias de las políticas tecnocientíficas destacan los costos prohibitivos de los créditos bancarios, la ausencia o distorsión de la banca de desarrollo, las compras gubernamentales que no exigen innovación a los proveedores y la desatención por la formación de mercados complementarios (García-Galván, 2014, 2015). Los aspectos financieros y macroeconómicos de la formación de capacidades innovadoras y de la interacción de las OPC-empresas han sido sistemáticamente menospreciados o pasados por alto. 
basadas en el conocimiento que impulsan las OPC, o por una pobre demanda general del conocimiento, lo cierto es que las relaciones colaborativas de las OPC con las empresas latinoamericanas se mantienen en un nivel que podría considerarse subdesarrollado.

\subsection{La tendencia de la investigación sobre la colaboración OPC-empresa en México}

En el análisis de las variables que reflejan las condiciones tecnocientíficas generales, que pueden propiciar e intensificar la colaboración OPC-empresas, destacan los trabajos de García-Galván $(2014,2015)$, quien dio cuenta de la inversión en tecnociencia e innovación, cobertura en educación superior, condiciones de financiamiento y demanda de conocimiento; por su parte, Mungaray et al. (2015) aportaron datos de actividades tecnocientíficas y conectividad; mientras que el trabajo de Sánchez et al. (2014) implicó un estudio con base en indicadores tecnocientíficos, laborales y de cobertura educativa.

De acuerdo con Mungaray et al., el principal factor asociado a la capacidad innovadora que impulsa el crecimiento y el desarrollo tecnológico de un país es que el entorno productivo (empresarial y competitivo) genere y demande innovaciones (2015: 23-31). También son importantes la capacidad de asimilación tecnológica, la institucionalidad (protección de los derechos de propiedad) y la participación universitaria en $\mathrm{I}+\mathrm{D}$.

A su vez, el trabajo de Sánchez et al. (2014: 140-144) representa un esfuerzo de monitorear la situación de las capacidades innovadoras en México. En su análisis, destaca que el país puede segmentarse en cinco regiones; aislando a la Ciudad de México, ${ }^{7}$ en cuanto a la capacidad innovadora, en primer lugar se encuentra la aglomeración industrial con potencial innovador, conformada por todos los estados de la frontera norte más Querétaro y Jalisco. Esta región tiene una estructura productiva más sólida, con industrialización elevada, así como infraestructura propicia para la generación de conocimiento, al contar

La Ciudad de México es considerada como la única región metropolitana con capacidad innovadora; cuenta con la mayor cantidad de recursos destinados a la innovación, a lo que se suma la estructura productiva y socioeconómica más fuerte en México (Sánchez et al., 2014: 149). Por ejemplo, de acuerdo con Torres y Jasso, entre los laboratorios farmacéuticos que colaboran con el Instituto de Investigaciones Biomédicas de la UNAM, hay 15 firmas extranjeras y mexicanas (2019: 10). 
con la mayor concentración de parques y centros tecnológicos. También tiene una mayor población con estudios de educación superior, además de una elevada concentración de grandes empresas nacionales y multinacionales.

Los resultados de Sánchez et al. (2014) confirman y aportan nuevas evidencias del potencial innovativo de varias entidades del norte de México que ya han sido objeto de estudio. Por ejemplo, Bajo (2006) y López-Leyva (2002) aportan evidencias para Baja California y Sonora; León et al. (2009) dan cuenta de las capacidades y potencialidades tecnocientíficas e innovadoras de Sonora, ${ }^{8}$ y Villasana (2011) aporta evidencias para el caso de Nuevo León.

Los casos de Chihuahua y Coahuila son interesantes porque, a pesar de ser los estados más extensos de México y de ser dispersos en la densidad poblacional e industrial, poseen potencialidades innovadoras y de colaboración OPC-empresas. Particularmente, son muy importantes las actividades maquiladoras y manufactureras de tecnologías medias en industrias como la automotriz, aeroespacial, metalmecánica, electrónica, entre otras. Ambas entidades cuentan con OPC de prestigio nacional e internacional capaces de cooperar con las empresas (De los Santos et al., 2017).

Es claro que para García-Galván $(2014,2015)$, Mungaray et al. (2015) y Sánchez et al. (2014), el entorno productivo caracterizado por la presencia de firmas propensas a innovar, de OPC, de infraestructuras que fomentan las actividades tecnocientíficas (parques tecnocientíficos y ciudades del conocimiento), así como una población con alta escolaridad que muestre preferencias por los productos, procesos y servicios intensivos en conocimiento, son condiciones necesarias para construir y fortalecer las capacidades innovadoras de los países y regiones.

Por otro lado, la investigación empírica microeconómica sobre la colaboración OPC-empresas se ha caracterizado por los estudios exploratorios y causales; destacan los que exploran las características gene-

8 Hay tres factores que influyen en la propensión de los investigadores hacia las actividades de transferencia y colaboración mediada por el conocimiento: factores contextuales (políticas de financiamiento y cultura en las áreas del conocimiento) y factores organizacionales y motivaciones, obstáculos percibidos individualmente. Pero las patentes, las spin-offs y la consultoría avanzada están lejos de constituirse como las actividades que prevalezcan dentro de las diversas modalidades de colaboración y transferencia de conocimiento (León et al., 2009: 89, 97, 107). 
rales de los actores colaborativos. Por ejemplo, las investigaciones de De Fuentes y Dutrénit (2012), León et al. (2009), Torres y Jasso (2019) y Villasana (2011) señalan las modalidades y los beneficios intelectuales y económicos de la colaboración para las OPC, y de formación de capacidades innovadoras para las firmas; el alcance de los acuerdos y los beneficios de corto plazo, así como el tipo de modalidad de colaboración más recurrente, según el área del conocimiento. Estas exploraciones coinciden con las propuestas teóricas y metodológicas de Arza (2010) y CEPAL (2010).

En otro ángulo se encuentra el trabajo de De Fuentes y Dutrénit (2014), quienes abordan la importancia de la proximidad geográfica, cognitiva y social para la cooperación OPC-empresas. En este sentido, se considera que la proximidad es importante para que la colaboración tenga éxito, debido a que implica cuestiones como el componente tácito, el acercamiento cognitivo, de acuerdo con el campo de conocimiento, y la confianza, entre otros aspectos.

El factor común de los trabajos sobre la colaboración OPC-empresas en México es que su principal unidad de análisis son los investigadores universitarios con experiencias en la colaboración tecnocientífica con las empresas. De este modo, De Fuentes y Dutrénit $(2012,2014)$ obtuvieron evidencias a partir de una encuesta aplicada a investigadores y a informantes clave de empresas. Por su parte, León et al. (2009) aplicaron una encuesta de alcance estatal, dirigida a académicos que laboraban en organizaciones de investigación y desarrollo de Sonora. Igualmente, Villasana (2011) realizó un estudio exploratorio basado en entrevistas a investigadores con experiencias en la colaboración de las organizaciones del conocimiento con las empresas. Una excepción fue el estudio de Torres y Jasso (2019) quienes, mediante entrevistas, indagaron sobre la perspectiva de los investigadores académicos y los empresarios usuarios del conocimiento universitario en el área de la salud.

De acuerdo con Torres y Jasso, el proceso de transferencia de tecnología requiere que los agentes tengan capacidades complementarias (2019: 11). Por el lado de las OPC, es indispensable que cuenten con capacidades para generar conocimiento transferible, gestionarlo y comercializarlo. La empresa, por su parte, necesita destrezas para identificar y asimilar el conocimiento requerido para estimular procesos de aprendizaje y de innovación tecnológica. Esquemáticamente, se trata de 
poner en correspondencia la oferta y la demanda de conocimiento. Sin embargo, en México una minoría de OPC cuenta con las capacidades para participar en actividades de patentamiento. Por otro lado, existe un reducido número de firmas con capacidades suficientes para absorber las innovaciones derivadas de las actividades de I+D de las OPC. A la luz de estas consideraciones, no es extraño que la transferencia de conocimiento, vía el licenciamiento y los contratos de transferencia de tecnología, no sea muy significativa. En esto hay coincidencia entre los trabajos de De Fuentes y Dutrénit $(2012,2014)$, León et al. (2009), Villasana (2011) y García-Galván (2014, 2015, 2018).

\subsection{La investigación reciente sobre la colaboración OPC- empresa en Baja California}

En la región noroeste de México (Baja California, Baja California Sur, Sonora y Sinaloa), los trabajos de López-Leyva (2002) y Bajo (2006) fueron pioneros en lo que a la colaboración OPC-empresas se refiere. Apoyados en el instrumental de los sistemas de innovación, destacan las potencialidades, las oportunidades y los desafíos de la colaboración basada en el conocimiento. Lo interesante de ambas investigaciones es que resaltan el papel de Baja California, en donde se asientan las principales OPC del noroeste.

El objetivo primordial de los estudios situados en Baja California ha sido la obtención de evidencias, ya sea sobre las capacidades tecnocientíficas e innovadoras de la región, o para demostrar las diversas actividades de colaboración OPC-empresas. Los fundamentos teóricos de estos se encuentran en la escuela evolucionista (Cabrera et al., 2017; Bajo, 2006; López-Leyva, 2002; López y Serrano, 2017), en la teoría de los recursos y las capacidades (Celaya y Barajas, 2012), y en el institucionalismo contemporáneo integrado (García-Galván, 2018; García-Galván et al., 2018). En la Tabla 1 se sintetizan los objetivos, las perspectivas metodológicas y los principales resultados de las investigaciones en Baja California. 
TABLA 1

RASGOS METODOLÓGICOS GENERALES Y RESULTADOS PRINCIPALES DE ESTUDIOS REALIZADOS

\begin{tabular}{|c|c|c|}
\hline Autores & Objetivo y aproximación metodológica & Principales resultados y conclusiones \\
\hline $\begin{array}{c}\text { Celaya y } \\
\text { Barajas } \\
(2012)\end{array}$ & $\begin{array}{c}\text { Analizar las capacidades de las OPC de Baja } \\
\text { California para realizar acciones de colaboración } \\
\text { con las empresas. Más de } 30 \text { entrevistas } \\
\text { semiestructuradas a actores clave de las OPC } \\
\text { y entes gubernamentales. Posteriormente, } \\
\text { aplicación de cuestionario (a investigadores) } \\
\text { en las OPC. }\end{array}$ & $\begin{array}{l}\text { La mayoría de las iniciativas de colaboración son contratos } \\
\text { esporádicos y poco formales. Tijuana y Mexicali cuentan } \\
\text { con mejores condiciones para la interacción con la } \\
\text { industria maquiladora y manufacturera; Ensenada, en } \\
\text { biotecnología y acuicultura. La mayoría de OPC tiene un } \\
\text { nivel bajo e intermedio de capacidades colaborativas. }\end{array}$ \\
\hline $\begin{array}{l}\text { Cabrera et al. } \\
\text { (2017) }\end{array}$ & $\begin{array}{l}\text { Analizar la actividad de las comunidades } \\
\text { científicas y los medios que utilizan para } \\
\text { socializar su conocimiento. Aplicación de } \\
\text { encuesta a investigadores de OPC ubicadas en } \\
\text { Ensenada. }\end{array}$ & $\begin{array}{c}\text { Menos de una cuarta parte de los encuestados establece } \\
\text { vínculos colaborativos con los actores del entorno, } \\
\text { incluyendo las empresas (únicamente } 17 \% \text { de los } \\
\text { investigadores difunden sus resultados con el sector } \\
\text { empresarial). }\end{array}$ \\
\hline $\begin{array}{c}\text { López y } \\
\text { Serrano } \\
\text { (2017) }\end{array}$ & $\begin{array}{l}\text { Analizar las etapas de aprendizaje del proceso } \\
\text { de la cultura de la innovación; identificar } \\
\text { los hallazgos e hitos claves en el desarrollo } \\
\text { institucional. La metodología fue cualitativa } \\
\text { (estudio de caso del CICESE: revisión } \\
\text { documental, de datos y entrevistas informales). }\end{array}$ & $\begin{array}{l}\text { Desde } 1990 \text { se observa una preocupación por las } \\
\text { capacidades tecnológicas, de innovación y colaboración } \\
\text { con la industria. Desde } 2000 \text { se observa fuerte } \\
\text { cooperación con ésta y con el gobierno en Baja } \\
\text { California. Énfasis en la transferencia de tecnología y el } \\
\text { emprendedurismo (el CICESE fue pionero en México en la } \\
\text { promoción de empresas de base tecnológica). }\end{array}$ \\
\hline $\begin{array}{c}\text { García-Galván } \\
\text { (2018) }\end{array}$ & $\begin{array}{l}\text { Contribuir a una mejor comprensión de la } \\
\text { colaboración tecnocientífica OPC-empresas. } \\
\text { El método fue el análisis de contenido de } \\
\text { convenios (con empresas), y de la planeación } \\
\text { institucional de la UABC. Entrevistas } \\
\text { semiestructuradas a directivos. }\end{array}$ & $\begin{array}{l}\text { El socio con el que más se colabora son las empresas } \\
\text { (disciplinas de las ingenierías y las tecnologías), pero } \\
\text { no significa que la colaboración sea intensiva en } \\
\text { conocimiento (los niveles de la consultoría avanzada } \\
\text { y de la transferencia de tecnología son marginales). } \\
\text { La modalidad de colaboración más frecuente es la } \\
\text { investigación bajo contrato. }\end{array}$ \\
\hline $\begin{array}{l}\text { García-Galván } \\
\text { et al. (2018) }\end{array}$ & $\begin{array}{l}\text { Identificar los principales rasgos y modalidades } \\
\text { de la colaboración, a través del conocimiento, } \\
\text { entre la UABC y las empresas, el gobierno y } \\
\text { la sociedad. Estudio cualitativo (entrevistas } \\
\text { semiestructuradas a } 21 \text { investigadores de la } \\
\text { UABC). }\end{array}$ & $\begin{array}{l}\text { La delimitación de la cooperación de la UABC con las } \\
\text { empresas, en la legislación y planeación institucional, es } \\
\text { ambigua. La principal modalidad de colaboración es la } \\
\text { de convenio o contrato. Obstáculos para la colaboración: } \\
\text { excesiva rotación del personal de apoyo, recursos } \\
\text { insuficientes, excesiva carga laboral y dificultad de } \\
\text { comunicación con las empresas. Principales fortalezas de } \\
\text { la UABC: infraestructura y equipamiento, capital humano } \\
\text { y capital reputacional. }\end{array}$ \\
\hline $\begin{array}{l}\text { García- } \\
\text { Galván, } \\
\text { Lindquist } \\
\text { y Morales } \\
\text { (2018) }\end{array}$ & $\begin{array}{c}\text { Analizar la dinámica de la colaboración } \\
\text { UABC-entorno (empresas). Estudio basado en } \\
\text { entrevistas semiestructuradas a directivos de los } \\
\text { institutos de investigación de la UABC. }\end{array}$ & $\begin{array}{l}\text { Existe poca colaboración con la industria. La modalidad } \\
\text { de colaboración más frecuente es la investigación bajo } \\
\text { contrato. Dentro de las fortalezas de los institutos está } \\
\text { haber construido capital reputacional, infraestructura y } \\
\text { equipamiento, y la formación de recursos humanos. Los } \\
\text { principales inhibidores de la cooperación son la excesiva } \\
\text { burocracia universitaria y la falta de difusión-divulgación } \\
\text { de productos y servicios. }\end{array}$ \\
\hline $\begin{array}{l}\text { Morales, } \\
\text { García-Galván } \\
\text { y Rodríguez } \\
\text { (2019) }\end{array}$ & $\begin{array}{l}\text { Identificar elementos normativos y de } \\
\text { la planeación estratégica que impliquen } \\
\text { manifestaciones de fomento a la cooperación } \\
\text { OPC-empresas. El método fue análisis deductivo } \\
\text { de contenido. }\end{array}$ & $\begin{array}{l}\text { Derivado de la revisión de la legislacióny de la planeación } \\
\text { nacional y estatal, al menos en el discurso institucional, } \\
\text { se observa interés por las actividades de producción } \\
\text { de conocimiento tecnocientífico y su aprovechamiento } \\
\text { mediante la cooperación OPC-empresas. }\end{array}$ \\
\hline
\end{tabular}

Fuente: elaboración propia con base en autores mencionados. 
En términos metodológicos, lo que nos muestra la Tabla 1 es que han existido importantes esfuerzos por investigar y comprender la dinámica de la colaboración tecnocientífica de las OPC con las empresas en Baja California; sin embargo, el común denominador de estas investigaciones es que han tenido como objeto de estudio a las organizaciones académicas. Así, el gran ausente en estas investigaciones son las empresas, por lo que resulta relevante recoger sus percepciones sobre la colaboración basada en el conocimiento que realizan con las OPC.

\section{Metodología}

Se realizaron entrevistas semiestructuradas a empresarios (representantes de organismos enfocados en la vinculación con las OPC). Se entrevistó a seis empresarios de las ciudades de Ensenada, Mexicali y Tijuana. ${ }^{9}$ Las asociaciones seleccionadas fueron:

-Ensenada: Consejo Coordinador Empresarial de Ensenada, Comité de Vinculación Escuela Empresa de Ensenada (COVEE).

-Mexicali: Comité de Vinculación Escuela-Empresa (Consejo de Desarrollo Económico de Mexicali).

-Tijuana: Comité de Vinculación Educativa de Tijuana (Consejo de Desarrollo Económico de Tijuana), Asociación de la Industria Maquiladora y de Exportación (Index Tijuana). Además, se integró un informante clave con experiencia laboral en lo académico, como funcionario gubernamental y como empresario.

En las entrevistas, semiestructuradas deductivas, de acuerdo con Brenner (2006), el investigador parte de constructos teórico-conceptuales y contextuales (desplegados en el primer apartado del artículo) en la investigación. El análisis procedió al examinar de qué manera los informantes se refirieron a los constructos durante la entrevista. Se

9 La elección de dichas sedes se fundamenta en la presencia de OPC de relevancia en investigación tecnocientífica en ellas. Es importante señalar que la existencia de estructuras orgánicas empresariales enfocadas en la promoción de la cooperación con las OPC no necesariamente implica una amplia e intensa colaboración tecnocientífica ni una profundización en las modalidades complejas. 
desarrollaron entrevistas enfocadas, en las que el entrevistador tuvo conocimiento de la CT del entrevistado con las OPC. También se dio al informante libertad para definir el contenido de sus aportaciones (Vela, 2001).

Un protocolo semiestructurado permite presentar a los informantes el mismo núcleo de preguntas, pero con libertad de incluir otras para complementar las respuestas. El protocolo (guion) incluyó 25 preguntas abiertas relacionadas con la CT OPC-empresas, agrupadas en cuatro dimensiones. Las preguntas ofrecieron un marco de referencia no restrictivo (Brenner, 2006; Cohen et al., 2007). La Tabla 2 describe a grandes rasgos las dimensiones del guion.

\section{Análisis de la información}

Las entrevistas fueron transcritas para facilitar su análisis a tráves del software Atlas.ti 7.0. La técnica para depurar las transcripciones fue el análisis de contenido, el cual permite probar constructos teóricoconceptuales y contextuales para mejorar el entendimiento de los datos. Además, se pueden agrupar palabras y frases que comparten significado en categorías relacionadas con el contenido (Elo y Kyngäs, 2008). También se consideraron las fases críticas propuestas por Brenner (2006): transcripción, descripción, análisis, interpretación y presentación.

Para Recuero (2014), el análisis incluye dos niveles: el textual y el conceptual. En el textual se seleccionó la información que podría ser útil en la siguiente fase. En el conceptual se establecieron relaciones entre categorías y códigos asignados. La última fase del análisis de las transcripciones incluyó el diseño de las redes semánticas, así como la interpretación correspondiente. La Tabla 3 detalla el proceso.

TABLA 2

DIMENSIONES DEL PROTOCOLO DE ENTREVISTA

\begin{tabular}{|c|c|}
\hline Expectativas y realidades & $\begin{array}{l}\text { Indaga las circunstancias en las que se llevó a cabo la CT en la práctica, en comparación con el } \\
\text { ideal de las mismas. }\end{array}$ \\
\hline $\begin{array}{l}\text { Evaluación externa de los } \\
\text { arreglos institucionales y } \\
\text { organizacionales }\end{array}$ & $\begin{array}{l}\text { Explora la opinión de las empresas acerca de la normatividad y organización existente al } \\
\text { interior de las OPC de Baja California, que regulan la CT OPC-empresas. }\end{array}$ \\
\hline Beneficios obtenidos & Cuestiona el beneficio obtenido por las empresas a través de la CT con OPC. \\
\hline Apoyo empresarial a la CT & Indaga el interés empresarial por coadyuvar en la CT con las OPC. \\
\hline
\end{tabular}

Fuente: elaboración propia. 
En la fase de segmentación se identificaron 19 citas de valor semántico. Posteriormente, en la revisión de las transcripciones, se establecieron cerca de 80 códigos abiertos, mismos que se depuraron para evitar redundancias y definir categorías mutuamente excluyentes y significativas. En la codificación selectiva se definieron familias y súper familias (Tabla 4).

Posteriormente, se obtuvieron las redes semánticas más importantes (respuestas más profundas y diversas por la mayor densidad, los nodos, las interconexiones, los vínculos semánticos); éstas se entienden como "un grafo en el cual los nodos o vértices etiquetados representan conceptos o características específicas, mientras que las líneas, también etiquetadas, representan vínculos de diversas clases entre conceptos" (Quillian, 1968: 130).

\section{TABLA 3}

NIVELES DE ANÁLISIS DE INFORMACIÓN CUALITATIVA

\begin{tabular}{ll}
\hline Segmentación de citas: fragmento del contenido con información relevante; dada su \\
contundencia, puede reportarse en los resultados de manera textual. \\
Codificación abierta: etiqueta que se agrega a un fragmento de la transcripción para resumir \\
la orientación del contenido. Existen tres códigos: el código in vivo es en donde, a falta de una \\
etiqueta apropiada, el cuerpo del texto se asume como nombre tentativo; el código "abierto" \\
es aquel que el investigador nombra a partir de la relación con el marco teórico-contextual; los \\
códigos "axiales" establecen un vínculo semántico entre dos códigos abiertos (Strauss, 2001). \\
Codificación selectiva: establece una categoría central que resume el objeto de investigación \\
(Strauss y Corbin, 2002). El análisis con Atlas.ti 7.0 permitió organizar los códigos en familias \\
(categorías) y súper familias (dimensiones). La designación de súper familias fue con base en las \\
dimensiones del guion de entrevistas. Por su parte, las familias se conformaron por los códigos \\
que representaron ideas afines sobre una temática particular.
\end{tabular}

Fuente: elaboración propia.

En cada red, los códigos se agrupan por la densidad (cantidad de veces mencionados) y su distribución es ascendente; de esta manera, los códigos más densos se muestran a la izquierda y los menos densos, a la derecha. Las flechas rojas indican las interconexiones entre los nodos de cada súper familia y sus familias de códigos. Las flechas negras representan la codificación axial, es decir, los vínculos entre conceptos. 
TABLA 4

SÚPER FAMILIAS Y FAMILIAS DE LA CT OPC-SECTOR PRODUCTIVO (SP)

\begin{tabular}{|c|c|c|}
\hline $\begin{array}{l}\text { Súper familias } \\
\text { (dimensiones) }\end{array}$ & Familias (categorías) & $\begin{array}{l}\text { Principales referentes para la } \\
\text { construcción de las familias }\end{array}$ \\
\hline \multirow[t]{2}{*}{$\begin{array}{l}\text { S1. Expectativas y } \\
\text { realidades }\end{array}$} & $\begin{array}{l}\text { F1. Potencialidades de las OPC para } \\
\text { incrementar la productividad y la } \\
\text { competitividad }\end{array}$ & $\begin{array}{l}\text { De Fuentes y Dutrénit (2014), Alcántar et } \\
\text { al. (2006). }\end{array}$ \\
\hline & F5. Limitaciones de las OPC para la CT & $\begin{array}{l}\text { ANUIES (2011, 2012); García-Galván } \\
\text { (2018). }\end{array}$ \\
\hline $\begin{array}{l}\text { S2. Evaluación } \\
\text { externa de arreglos } \\
\text { institucionales y } \\
\text { organizacionales }\end{array}$ & $\begin{array}{l}\text { F3. Destrezas de los gestores de la } \\
\text { cooperación }\end{array}$ & Gould-Bei (2002). \\
\hline S3. Beneficios obtenidos & $\begin{array}{l}\text { F1. Beneficios esperados a corto plazo } \\
\text { por las empresas }\end{array}$ & $\begin{array}{l}\text { De Fuentes y Dutrénit (2014), Arza } \\
\text { (2010). }\end{array}$ \\
\hline $\begin{array}{l}\text { S4. Apoyo a la CT desde } \\
\text { el SP }\end{array}$ & $\begin{array}{l}\text { F2. Programas para mejorar la } \\
\text { colaboración con las OPC }\end{array}$ & Bajo (2006), Celaya y Barajas (2012). \\
\hline
\end{tabular}

\section{RESULTADOS Y DISCUSIÓN}

Los resultados del estudio caracterizan, principalmente, la dinámica del primer nivel de colaboración OPC-empresas identificado por la CEPAL (2010: 65-80) y, en menor medida, el nivel dos, en donde las relaciones se distinguen por un uso intermedio del conocimiento. El nivel tres se descarta, en tanto que los participantes no desarrollan una CT intensiva y compleja. Los resultados también pueden enmarcarse en los cuadrantes 1 y 2 de la propuesta de Arza (2010), que delinea procesos pasivos de CT. Éstos implican una colaboración unidireccional, en donde las firmas capitalizan los servicios de las OPS para eficientizar sus propios procesos.

\section{Sobre las expectativas y realidades (S1) de la CT}

La Figura 1 presenta las potencialidades de las OPC para incrementar la productividad y la competitividad (S1.F1). Como se observa, las categorías más densas fueron: "Fortalecer esquemas de difusión y comunicación", seguida de "Fortalecer la vinculación estudiantil". En contraste, las potencialidades menos densas fueron: "Exposición a la innovación", "Situación geográfica", "Reestructuración de comités de vinculación" y el "Fomento a las ciencias de la salud e ingeniería". Esta baja densidad puede obedecer a que representan factores internos de las 
OPC, a diferencia de las categorías más densas en donde se enfatiza la interacción con las empresas.

FIGURA 1

POTENCIALIDADES DE LAS OPC PARA INCREMENTAR LA PRODUCTIVIDAD Y LA COMPETITIVIDAD

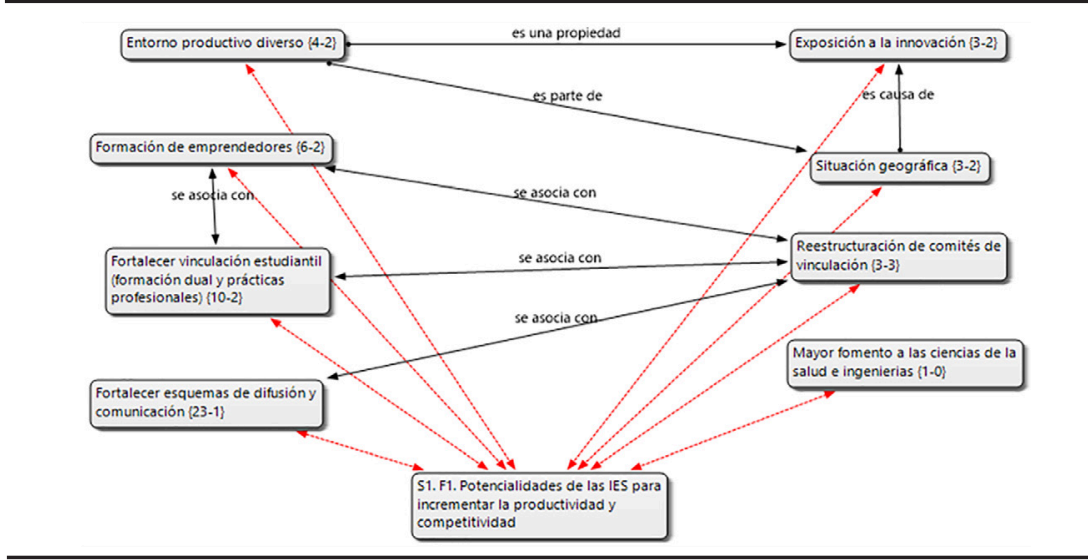

Fuente: elaboración propia.

Destaca la poca importancia otorgada a la distancia geográfica de las OPC respecto de las empresas, tema discutido por De Fuentes y Dutrénit (2014); y el desconocimiento de la importancia del desarrollo de las ingenierías y de las ciencias de la salud como coadyuvantes para la generación de conocimiento tecnocientífico (De Fuentes y Dutrénit, 2012).

La necesidad de fortalecer los esquemas de comunicación fue establecida para la UABC, desde hace más de una década, por Alcántar et al. (2006), quienes propusieron una revaloración de las políticas, criterios y estrategias de promoción y divulgación de esta casa de estudios. Sin embargo, las respuestas de los entrevistados indican que esta deficiencia no se ha corregido:

"Yo creo que sí nos falta. Nos falta esa difusión, la creación de directorios fáciles de encontrar, con las capacidades, con los ejemplos; y a su vez, también, desde el sector productivo, faltan [...] esas necesidades que también podrían darse de alta en algún banco de datos en donde estemos viendo para hacer un match [...] Pero te puedo decir, desde el lado empresarial, que son muy poco conocidas las ventajas y las capacidades que tienen: "no cacaraqueamos el 
huevo" para que los empresarios identifiquen que se pueden hacer más proyectos de vinculación en investigación y desarrollo tecnológico [...]. Entonces sí debe haber una reestructuración, tanto de los presupuestos como de la talla de [anuncios] comerciales de las mismas universidades para que puedan vender lo que saben hacer" (ENT2, 18 de mayo de 2018).

Respecto a la necesidad de fortalecer la colaboración estudiantil, los entrevistados expresaron: "La otra área de oportunidad es el fortalecimiento de los programas de prácticas profesionales [...] Está el Programa Mexicano de Formación Dual, por ejemplo, que está inspirado en Alemania, también hay otros inspirados en Francia trabajando en México, hay varios modelos de formación dual que bien valdría la pena que las universidades mexicanas realmente adoptaran, pero eso implica cambios burocráticos" (ENT1, 17 de mayo de 2018). "El estudiante, aunque esté en la institución educativa, y que esté académicamente bien preparado, cuando llega a la industria se encuentra con que hay que ser novedosos, cosas que ellos no consideraban. Entonces, llegan y tiene que volvérseles a entrenar" (ENT6, 19 de junio de 2018).

También se cuestionó a los entrevistados acerca de las limitaciones que presentan las OPC de Baja California para llevar a cabo actividades de CT (Figura 2, S1.F5).

La principal limitación identificada es la CT deficiente: "Si seguimos teniendo las mismas prácticas de burocracia, de no vincularnos, no lo vamos a resolver [...] Es una pesadilla la vinculación (ENT7, 17 de agosto de 2018).

Esto concuerda con otros hallazgos, como los de la ANUIES (2011, 2012) y García-Galván (2018), en los cuales la CT deficiente incluye aspectos como la burocracia universitaria excesiva, ritmos administrativos contrapuestos e inexistencia de esquemas institucionales de incentivos. "El otro tema que podría ser burocrático, es que, precisamente, como los investigadores tienen sus tiempos académicos y sus tiempos de vacaciones, pues a veces hay cosas que no fluyen en épocas de vacaciones. [...] ahí se atoran los proyectos. Entonces, la dinámica del sector empresarial es diferente y a veces no nos atrevemos a hacerlo, por lo mismo. Yo creo que tenemos que encontrar ese dinamismo" (ENT2, 18 de mayo de 2018). 
FIGURA 2

LIMITACIONES DE LAS OPC PARA LA CT

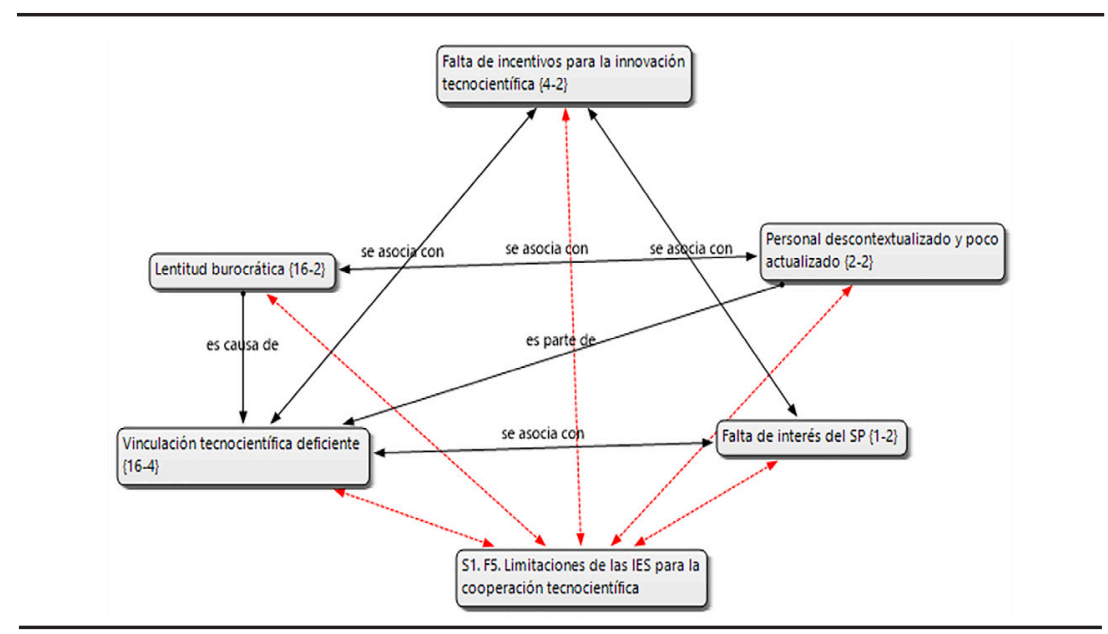

Fuente: elaboración propia.

\section{Evaluación externa de los arreglos institucionales- organizacionales (S2)}

Acerca del perfil idóneo del personal dedicado a la gestión de la colaboración, las respuestas más densas fueron: "Conocimiento organizacional IES y SP" y "Habilidades de marketing y relaciones públicas" (Figura 3, S2.F3).

Las aportaciones de los participantes incluyeron comentarios como: "Que sea alguien capaz de bosquejar la forma de resolver los requerimientos de la empresa, alguien que llegue a una empresa y pueda visualizar cómo lo resuelve, no necesariamente con las capacidades propias de su institución, alguien que pueda integrar equipos para resolver problemas" (ENT2, 18 de mayo de 2018). "Pues deben conocer perfectamente bien a su institución [...], deben conocer cuál es la capacidad que tiene su institución, para ver si pueden o no pueden con el proyecto. No queremos que nos digan 'espérame, voy a preguntar', queremos que vengan bien informados" (ENT6, 19 de junio de 2018).

La necesidad de que los gestores de la cooperación posean habilidades de marketing y relaciones públicas se expresa en estos términos: "Se necesitan vinculadores publirrelacionistas: que sepan dar una plática, que sepan ir a la empresa con ejecutivos, que se puedan sentar a cenar con una empresa porque le va a abrir ocho o diez becas y va 
a contribuir a la calidad institucional. Esa parte necesita profesionalizarse. Yo la verdad no veo, salvo honrosísimas excepciones, casos de este tipo" (ENT1, 17 de mayo de 2018).

FIGURA 3

DESTREZAS DE LOS GESTORES DE LA COLABORACIÓN

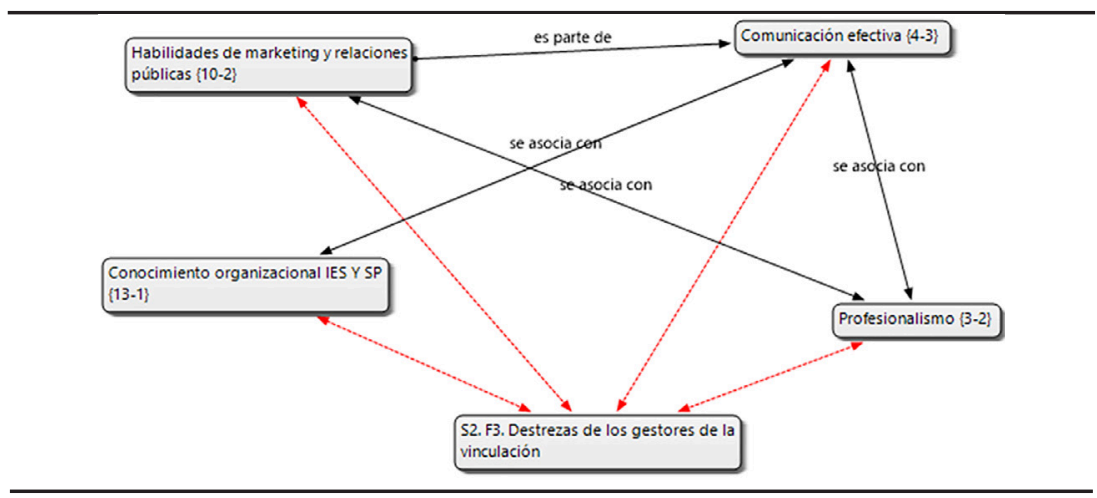

Fuente: elaboración propia.

La respuesta coincide con Gould-Bei, quien destaca que la buena administración de la cooperación al interior de las OPC requiere personal altamente calificado que cuente con amplios conocimientos y experiencias en materia de "vinculación, administración, educación y vida académica, tecnología, mercadotecnia y ventas, empresa y negocios" (2002: 405). Además, dicho personal debe entender la cultura académica y tener amplias relaciones con las empresas.

\section{Beneficios obtenidos (S3)}

En la Figura 4, S3.F1 se muestran los beneficios esperados a corto plazo por las empresas, derivados de las actividades de la CT OPC-empresas. Algunas de las aportaciones fueron: "A corto plazo, la incorporación de talento fresco, la incorporación de nuevas formas de pensar, inclusive de nuevas tecnologías en el manejo de los casos. Porque uno ya trae ideas viejas" (ENT1, 17 de mayo de 2019); "Cuando llega un joven de universidad, o un maestro, o un doctor, estamos permitiendo que llegue nuevo conocimiento, o maneras distintas de poder hacer las cosas" (ENT2, 18 de mayo de 2019); "podríamos estar capacitando a las personas que el día de mañana van a trabajar con nosotros, o estar capacitando a las personas que el día de mañana van a ser empresarios, 
de una manera directa, y tendríamos, cuando ellos egresen, la mano de obra exacta que necesitamos" (ENT4, 31 de mayo de 2018).

FIGURA 4

BENEFICIOS ESPERADOS A CORTO PLAZO POR LAS EMPRESAS

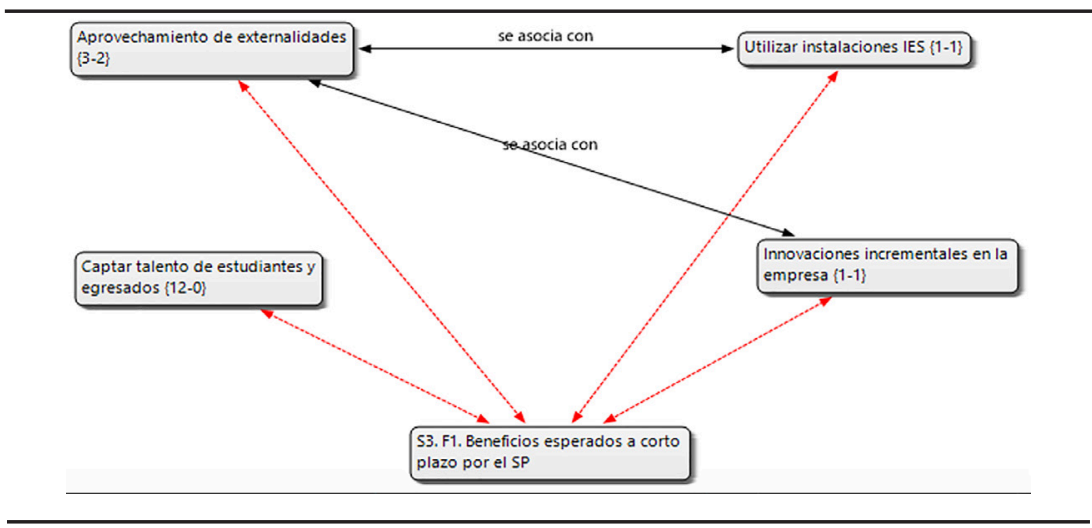

Fuente: elaboración propia.

Las respuestas sobre los beneficios a corto plazo para las empresas coinciden parcialmente con la CEPAL (2010), la cual destaca que la cooperación OPC-empresas, a través de proyectos conjuntos, permite a las empresas beneficios como la resolución de problemas específicos y el acceso a laboratorios y a otros recursos de las universidades. Asimismo, De Fuentes y Dutrénit (2012) señalan que las empresas se interesan en identificar empleados potenciales en las OPC, así como en el acceso a fuentes de conocimiento, que puedan conducir a aplicaciones industriales.

\section{Apoyo a la CT desde las empresas (S4)}

En relación con los programas de las empresas para mejorar la cooperación con las OPC (Figura 5, S4.F2), destacan las menciones hacia la "Formación dual".

Entre las menciones sobre la formación dual destacan: "estamos llevando al sector productivo los modelos de formación dual. El modelo de formación dual es aquel en donde el joven, en su último año de formación, está $100 \%$ en la empresa, en un proceso de rotación de materias sustitutas por materias en la empresa" (ENT2, 18 de mayo de 2018). "Con la educación dual [...] le permites al empresario[...] 
trabajar como él $[\ldots]$ y enseñar al joven $[\ldots]$ cómo funcionan las cosas en la empresa [...]. Eso es importantísimo" (ENT4, 31 de mayo de 2018).

\section{Aportaciones adicionales de informante clave}

Se presenta el testimonio de un empresario sui géneris. Él es relevante en la medida en que, además de tener experiencia como académico, ha fundado empresas de base tecnocientífica de alcance internacional, y ha prestado sus servicios como funcionario gubernamental en áreas relacionadas con el fomento de la tecnología y la innovación. En la Tabla 5 se presentan los testimonios.

FIGURA 5

PROGRAMAS PARA MEJORAR LA COLABORACIÓN CON LAS OPC

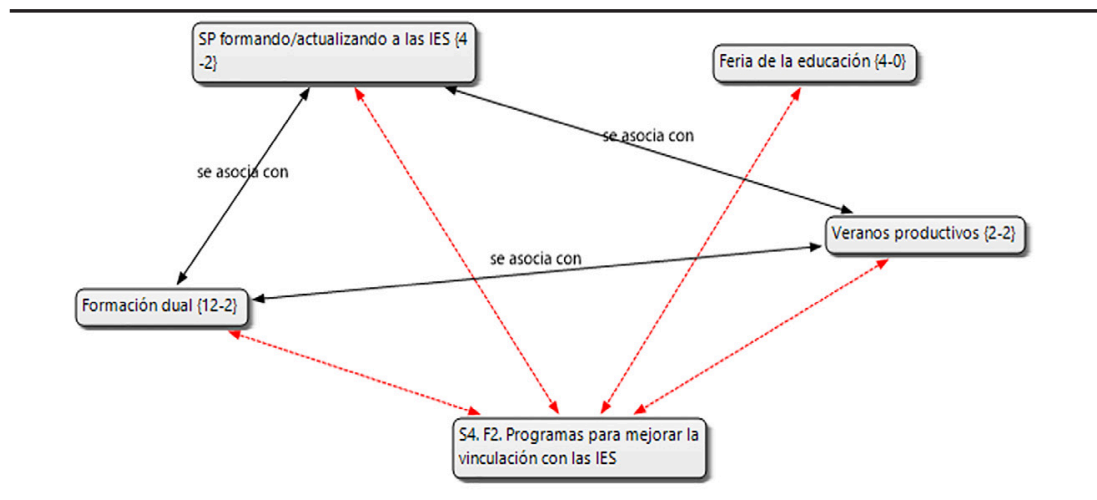

Fuente: elaboración propia

Las aportaciones de este investigador se sumaron a la perspectiva de otros empresarios, así como otros estudios regionales; por ejemplo, Bajo (2006), Celaya y Barajas (2012). 
TABLA 5

COMENTARIOS IMPORTANTES DEL INFORMANTE CLAVE

\section{Aspectos relevantes}

Incorporación de nuevos

indicadores en el SNI para incentivar la CT

\section{Comentarios asociados}

"Se tienen que modificar los incentivos, no nada más tomar en cuenta los artículos científicos [...], hay que ver cómo incentivamos la vinculación [...]. Si sabemos que está fallando, ¿̇por qué no hacemos nada para poner indicadores para medirla? [...] desde luego, tanto el Conacyt como las universidades tendrían que estar poniendo indicadores de vinculación".

Benchmarking como estrategia para mejorar la colaboración OPCempresas “una universidad exitosa es el Tec de Monterrey. Entonces, ¿qué está haciendo [...] que nosotros no? ¿Por qué no reconocer la distancia y ver qué podemos hacer como ellos? Hay cosas que no están funcionando. Tenemos que ver quién es el mejor en la vinculación, es benchmarking".
Ambiente empresarial adverso para CT “así como hay malos académicos y políticos, también hay malos empresarios. Gente que no invierte en el capital humano. Quieren que las universidades 'se las den papita'

(sic): que estén bien formados, que hablen inglés, que conozcan del oficio; quieren todo. Piensan, a veces, que por pagar impuestos son merecedores de todo".

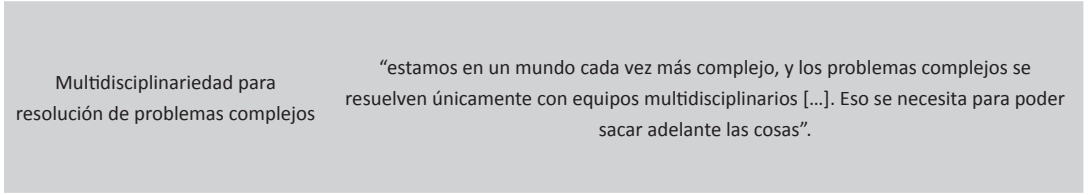

"me pidieron que me vinculara con la Universidad de San Diego, y le dije

Necesidad de formalizar

la colaboración a partir de aspectos culturales asignación de las inversiones en ciencia y tecnología a mi director que no porque los gringos son muy profesionales. Aquí no podemos jugar a la vinculación. Si vamos a hacer algo, tenemos que poner un calendario. Y yo pensé, '¿con qué equipo cuento aquí para aventarme una bronca en ese sentido?'; [...] los norteamericanos son formales, no juegan".

\begin{tabular}{|c|c|}
\hline $\begin{array}{l}\text { Necesidad de mejorar la } \\
\text { asignación de las inversiones } \\
\text { en ciencia y tecnología }\end{array}$ & $\begin{array}{l}\text { "El gobierno tiene que invertir, pero monitorear. Invertir hasta lograr un } \\
\text { piso [...] Pero, si nosotros hacemos un análisis comparativo entre lo que } \\
\text { se invierte en tecnología en México [...], hay países que invierten menos } \\
\text { que nosotros, pero tienen más resultados. El problema no se va a resolver } \\
\text { echándole más dinero; si seguimos teniendo las mismas prácticas de } \\
\text { burocracia, de no vincularnos, no lo vamos a resolver". }\end{array}$ \\
\hline $\begin{array}{c}\text { Competencias educativas que } \\
\text { impactan en la colaboración } \\
\text { OPC-empresas }\end{array}$ & $\begin{array}{l}\text { "Los norteamericanos implementaron un programa que se llama } \\
\text { STEM (Science, Technology, Engineering, and Mathematics), desde las } \\
\text { primarias. Sería como ese STEM implementarlo en México. Necesitamos } \\
\text { más ingenieros, pero todo mundo le da la vuelta a las matemáticas. [...] } \\
\text { Necesitamos ver eso, y también ver cómo, a través de la política pública, } \\
\text { rescatamos el inglés [...], nos guste o no, el inglés es el tema (sic) de los } \\
\text { negocios y también de la ciencia y la tecnología". }\end{array}$ \\
\hline
\end{tabular}

Fuente: elaboración propia. 


\section{CONCLUSIONES}

La región latinoamericana se caracteriza por un déficit general de empresas innovadoras y por la prevalencia de firmas dedicadas a la manufactura, la importación, el comercio y los servicios. Asimismo, se ha señalado que los estudios sobre la colaboración OPC-empresas han privilegiado la perspectiva de los actores académicos, por lo que ha relegado la visión de los empresarios. En este sentido, la contribución teórica del presente trabajo consistió en aprovechar dicho vacío en la investigación para construir una visión conjunta sobre el fenómeno de la colaboración OPC-empresas.

En el ámbito de las potencialidades de las OPC para incrementar la productividad y la competitividad, los empresarios señalaron que el principal desafío radica en el fortalecimiento de los canales de difusión y comunicación (directorios, catálogos y bases de datos) sobre los resultados, productos y servicios de las OPC. Además, identificaron que la colaboración basada en los estudiantes puede traducirse en la captación y formación temprana de futuros empleados. En cuanto a las limitaciones, hubo consenso al afirmar que el principal obstáculo para la vinculación en las OPC es la lentitud administrativa propiciada por la burocracia.

En relación con el perfil del personal para desarrollar funciones y actividades de colaboración, las OPC deben apostar por su profesionalización. Este tipo de profesional debe contar con competencias transversales (desempeñarse bien en el ámbito académico, pero también en los asuntos empresariales) y tener habilidades de comunicación interorganizacional.

El mecanismo con el que las empresas podrían contribuir, mayormente, al desarrollo de la CT es la formación dual de estudiantes y graduados, así como a través de las interacciones para la formación y la actualización continua. A su vez, en la perspectiva política, se requieren nuevos incentivos para impulsar la $\mathrm{CT}$, incrementar la inversión en I+D y fomentar las habilidades matemáticas y lingüísticas (inglés); asimismo, emular las mejores prácticas nacionales. Por parte de los empresarios, se requiere más propensión al riesgo para fundar empresas tecnocientíficas.

Una de las limitaciones del estudio es que se trata de un análisis exploratorio basado en siete entrevistas a empresarios de Baja Cali- 
fornia, México. Dado esto, para futuros esfuerzos de investigación sería conveniente recoger, mediante una encuesta, las percepciones, posturas y opiniones de todos los empresarios de la región. También, sería conveniente replicar las estrategias de este análisis en otras regiones del país, y considerar la posibilidad de entrevistar a funcionarios relacionados con las políticas tecnocientíficas y universitarias.

Los esfuerzos mencionados guardan simetría con los análisis realizados por Arza (2010), Arocena y Sutz (2010), y Bodas et al. (2013) en países sudamericanos. Esencialmente, la agenda propuesta en el presente trabajo se concentra en explorar aquellos elementos que ya han brindado información relevante sobre la cooperación OPC-empresas en otras latitudes, como la ampliación del trabajo empírico y la integración de distintos enfoques y corrientes investigativas.

\section{BIBLIOGRAFÍA}

Alcántar, Víctor, José Luis Arcos y Alejandro Mungaray (2006), Vinculación y posicionamiento de la Universidad Autónoma de Baja California con su entorno social y productivo, México: UABC-ANUIES.

Arocena, Rodrigo y Judith Sutz (2005), "Latin American Universities: From an Original Revolution to an Uncertain Transition", Higher Education, 50(4), pp. 573-592.

Arocena, Rodrigo y Judith Sutz (2010), "Weak knowledge demand in the South: learning divides and innovation policies", Science and Public Policy, 37(8), pp. 571-582.

Arrow, Kenneth (1962 [1979]), "El bienestar económico y la asignación de recursos para la invención”, en Nathan Rosenberg (ed.), Economía del cambio tecnológico, México, FCE, pp. 151-167.

Arza, Valeria (2010), "Channels, benefits and risks of public-private interactions for knowledge transfer: conceptual framework inspired by Latin America", Science and Public Policy, 37(7), pp. 473-484.

Asociación Nacional de Universidades e Instituciones de Educación SuperiorFESE (2011), Manual de la vinculación educación superior-empresa. México, ANUIES / Fundación Educación Superior-Empresa.

Asociación Nacional de Universidades e Instituciones de Educación Superior (2012), Plan de Desarrollo al 2016. Hacia la Proyección de la Vinculación de las IES para la Innovación Orientada al Desarrollo Sustentable de las Regiones en México, México.

Audretsch, D., B. Bozeman, K. Combs, M. Feldman, A. Link, D. Siegel, P. Stephan, G. Tassey y C. Wessner (2002), "The Economics of Science and 
Technology", The Journal of Technology Transfer, 27(2), pp. 155-203. $<$ https://link.springer.com/article/10.1023/A:1014382532639>.

Bajo, Alonso (2006), Vinculación e innovación en la región noroeste de México. México, Universidad Autónoma de Sinaloa.

Bekkers, Rudi e Isabel María Bodas (2008), “Analysing knowledge transfer channels between universities and industry: To what degree do sectors also matter?", Research Policy, 37(10), pp. 1837-1853.

Bodas, Isabel María, Rosane Argou y Evando Mirra (2013), "University-industry collaboration and innovation in emergent and mature industries in new industrialized countries", Research Policy, 42(2), pp. 443-453.

Brenner, Mary E. (2006), "Interviewing in Educational Research", en Judith Green, Gregory Camilli y Patricia Elmore (eds.), Handbook of Complementary Methods in Education Research, Mahwah, NJ, USA, Lawrence Erlbaum Associates / American Educational Research Association, pp. 357-370.

Bush, Vannevar (1999 [1945]), “Ciencia, la frontera sin fin. Un informe al presidente, julio de 1945", REDES, 6(14), pp. 89-156.

Cabrera, Mayer, Santos López-Leyva y Arturo Serrano (2017), "Relevancia, pertinencia y socialización del conocimiento, ¿cómo contribuyen los investigadores a la innovación de Ensenada, México?", Investigaciones Regionales-Journal of Regional Research, 37, pp. 31-53.

Caloghirou, Y., S. Ioannides y N. Vonortas (2008), "Research Joint Ventures: A Critical Survey of the Theoretical and Empirical Literature", Working Paper. <https://onlinelibrary.wiley.com/doi/abs/10.1111/1467-6419.00204>.

Celaya, Minerva y María del Rosío Barajas (2012), "La academia y el sector productivo en Baja California. Los actores y su capacidad de vinculación para la producción, difusión y trasferencia del conocimiento y la innovación”, Región y sociedad, (55), pp. 41-80.

Cereijido, Marcelino (2008), Por qué no tenemos ciencia, México, Siglo XXI Editores.

Cohen, Louis, Lawrence Manion y Keith Morrison (2007), Research methods in education, London and New York, Routledge.

Comisión Económica para América Latina y el Caribe (CEPAL) (2010), Espacios iberoamericanos: vínculos entre universidades y empresas para el desarrollo tecnológico, Santiago de Chile.

Dasgupta, Partha y Paul David (1994), "Toward a new economics of science", Research Policy, 23, pp. 487-521.

David, Paul y Dominique Foray (2002), "Una introducción a la economía y a la Sociedad del saber". Revista Internacional de Ciencias Sociales, 171. $<$ https://www.oei.es/historico/salactsi/david.pdf $>$.

De Fuentes, Claudia y Gabriela Dutrénit (2012), "Best channels of academiaindustry interaction for long-term benefit", Research Policy, 41(9), pp. 1666-1682. 
De Fuentes, Claudia y Gabriela Dutrénit (2014), “Geographic proximity and university-industry interaction: the case of Mexico", The Journal of Technology Transfer, 41(2), pp. 329-348.

De los Santos, Saúl, Jorge Carrillo, Ismael Plascencia, Daniel Villavicencio e Ilse Esparza (2017), Ecosistemas de innovación en la frontera norte: Chihuahua y Coahuila, México, El Colegio de la Frontera Norte y COMECSO.

Elo, Satu y Helvi Kyngäs (2008), "The qualitative content analysis process", Journal of Advanced Nursing, 62 (1), pp. 107-115.

Etzkowitz, Henry (2003), "Research groups as 'quasi-firms': the invention of the entrepreneurial university", Research Policy, 32, pp. 109-121.

Foray, Dominique (2004), Economics of Knowledge, Cambridge, MA, The MIT Press.

García-Galván, Rodolfo (2014), “Desempeño económico y factores que se encuentran detrás del rezago tecnocientífico en México", Cofactor. Revista del Consejo de Investigación y Evaluación de la Política Social, (9), pp. 111-146.

García-Galván, Rodolfo (2015), "Cinco factores que inhiben la colaboración tecnológica universidad-empresa en los países en desarrollo”, Tiempo Económico, 29(10), pp. 67-80.

García-Galván, Rodolfo (2018), "El papel de las instituciones y de la colaboración universidad-empresa en el desarrollo: evidencias de la UAEMÉX y la UABC", Paradigma económico, (1), pp. 81-118.

García-Galván, Rodolfo, Mayer Cabrera y Lewis McAnally (2018), "La colaboración tecnocientífica de la universidad con su entorno en México: El Caso de la Universidad Autónoma de Baja California”, Archivos Analíticos de Politicas Educativas, 26(140), pp. 1-32.

García-Galván, Rodolfo, Ricardo Lindquist y Marcela Morales (2018), “La colaboración de la universidad con el entorno: la perspectiva de los directivos de los institutos de investigación de la UABC", en Julieta Flores, Irma Leticia Garza y Ana Irene Cuevas (eds.), Universidad y diversidad en educación, una visión multidisciplinaria. Tendencias educativas y responsabilidad social, Monterrey, Universidad Autónoma de Nuevo León, pp. 22-35.

Gould-Bei, Giacomo (2002), La administración de la vinculación: cómo hacer qué. Tomo II, México, ANUIES.

León, Jorge Inés, Santos López-Leyva y Sergio Sandoval (2009), “Actividades de transferencia del conocimiento de los investigadores académicos en el estado de Sonora", Revista de la Educación Superior, 38(151), pp. 85-111.

López, Carlos Gerardo y Artuto Serrano (2017), "Hacia el surgimiento de una cultura de la innovación en un centro público de investigación en México: hallazgos y aprendizajes", Revista Electrónica Nova Scientia, 9(9), pp. 313-341. 
López-Leyva, Santos (2002), "La vinculación y los investigadores”, Perfiles Educativos, 24(98), pp. 76-95.

Morales, Marcela (2019), Cooperación tecnocientifica IES-Sector productivo desde la perspectiva del cambio institucional. Evidencias de Baja California, tesis doctoral, México, UABC.

Morales, Marcela, Rodolfo García-Galván y Juan Carlos Rodríguez (2019), "Contexto institucional de la cooperación IES-sector productivo: marco general para México y Baja California”, en Alicia A. Chaparro, Juan Carlos Rodríguez, y Juan Carlos Pérez (eds.), Apuntes de investigación educativa, México: Qartuppi, pp. 188-209.

Mowery, David y Bhaven Sampat (2005), "The Bayh-Dole Act of 1980 and University-Industry Technology Transfer: A Model for Other OECD Governments?", The Journal of Technology Transfer, 30 (1-2), pp. 115-127.

Mungaray, Alejandro, Jesús A. Ríos, José G. Aguilar y Martín A. Ramírez (2015), "La capacidad innovadora de la economía mexicana", Economía Teoría y Práctica, 43, pp. 11-36.

Naidorf, Judith (2014), "Knowledge utility: From social relevance to knowledge mobilization", Education Policy Analysis Archives, 22(89), pp. 1-31.

Nelson, Richard (1959 [1979]), "La economía sencilla de la investigación científica básica”, en Nathan Rosenberg (ed.), Economía del cambio tecnológico, México: FCE, pp. 136-150.

Pérez, Ruy (2010), Reflexiones sobre la ciencia, México, El Colegio Nacional.

Perkmann, M., V. Tartarik, M. McKelveyb, E. Autio, A. Broström et al. (2013), "Academic engagement and commercialisation: A review of the literature on university-industry relations". Research Policy, 42, pp. 423-442. $<$ https://cyberleninka.org/article/n/239211.pdf $>$.

Quillian, Ross (1968), "Semantic memory”, en Marvin Minsky (ed.), Semantic information processing, Cambridge: MIT Press, pp. 27-70.

Recuero, Nuria (2014), La orientación al mercado en los yacimientos arqueológicos, Madrid, Universidad Complutense de Madrid.

Riquelme, Graciela y Ariel Langer (2008), "Las capacidades de los grupos universitarios frente a las demandas sociales y productivas: perspectiva de los investigadores-docentes sobre las lógicas de producción y circulación del conocimiento", en Graciela Riquelme (ed.), Las universidades frente a las demandas sociales y productivas. Capacidades de los grupos de docencia e investigación en la producción y circulación de conocimiento, Argentina, Miño y Dávila Editores, pp. 475-561.

Sánchez, Yesenia, Francisco García y José E. Mendoza (2015), “La capacidad de innovación y su relación con el emprendimiento en las regiones de México", Estudios Gerenciales, 31(136), pp. 243-252.

Strauss, Anselm (2001), Qualitative analysis for social scientists, Reino Unido, Cambridge University Press.

Strauss, Anselm y Juliet Corbin (2002), Bases de la investigación cualitativa. 
Técnicas y procedimientos para desarrollar la Teoría Fundamentada, Medellin, Universidad de Antioquia.

Torres, Arturo y Javier Jasso (2019), “Capabilities and knowledge transfer: evidence from a university research center in the health area in Mexico", Contaduría y Administración, 64(1), pp. 1-16.

Vela, Fortino (2001), "Un acto metodológico básico de la investigación social: la entrevista cualitativa", en María Luisa Tarrés (coord.), Observar, escuchar y comprender sobre la tradición cualitativa en la investigación social, México, Colmex / FLACSO, pp. 63-95.

Villasana, Marcia (2011), "Fostering university-industry interactions under a triple helix model: The case of Nuevo Leon, Mexico", Science and Public Policy, 38(1), pp. 43-53. 